\title{
In vitro study on anti-cancer properties of genistein in tongue cancer
}

This article was published in the following Dove Press journal:

OncoTargets and Therapy

13 November 2017

Number of times this article has been viewed

\section{Fatima Ardito \\ Mario R Pellegrino \\ Donatella Perrone \\ Giuseppe Troiano \\ Armando Cocco \\ Lorenzo Lo Muzio}

Department of Clinical and Experimental Medicine, Foggia University, Foggia, Italy
Correspondence: Lorenzo Lo Muzio Department of Clinical and Experimental Medicine, University of Foggia, Via

Rovelli, 50-7| I 22 Foggia, Italy

Tel +39088I 588090

Fax $+39088 \mid 58808$ I

Email lorenzo.lomuzio@unifg.it
Purpose: Tongue cancer is an extremely aggressive disease and is characterized by a poor prognosis. It is a complex disease to treat and current therapies have produced mediocre results with many side effects. Some facts suggest that natural essences can support traditional cancer therapy by carrying out a synergistic function with chemotherapy. Therefore, we evaluated the antitumor effects of genistein on tongue carcinoma cells.

Methods: Genistein 20, 50 and $100 \mu \mathrm{M}$ were used for 24, 48 and 72 hours on 3 tongue carcinoma cell lines. xCELLigence system was used to evaluate the effects on cell adhesion, proliferation and to calculate $\mathrm{IC}_{50}$ values. Both MTT assay and Trypan blue assay were used to evaluate alterations in cell viability, scratch assay for cell migration and Western blot analysis for expression of some proteins.

Results: Cell adhesion was inhibited especially between 20 and $50 \mu \mathrm{M}$ of genistein treatment. Proliferation was reduced by $50 \%$ for treatments with $20 \mu \mathrm{M}$ at 24 hours, with 20 or $50 \mu \mathrm{M}$ at 48 and $50 \mu \mathrm{M}$ at 72 hours $(P<0.0001)$. Viability tests confirmed a proportional reduction in concentration of genistein and duration of treatments. Even cell migration was reduced significantly $(P<0.001)$. Genistein down-regulates vitronectin, OCT4 and survivin.

Conclusion: This in vitro study clarifies the anti-tumor effect of genistein on tongue carcinoma. In vivo studies are needed to confirm these data and develop a suitable delivery system that is capable of acting directly on tumor.

Keywords: genistein, tongue cancer, xCELLgence system, cell adhesion, cell proliferation

\section{Introduction}

Tongue cancer is the most common tumor of oral squamous cell carcinoma (OSCC). Survival rates at 5 years since diagnosis appears stable, despite new treatments. ${ }^{1-3}$ In addition, the side effects have not been completely eliminated.

This has led to a growing interest in researching new molecules with selective effects against cancer cells without causing any damage to healthy cells and tissues.

Genistein (4',5,7-trihydroxyisoflavone) is an isoflavone, found in soybeans and all its derivatives such as flour, sauces, oil, milk and cheese. ${ }^{4}$ It is also found in other legumes such as lentils, beans, peas, chickpeas and whole grains such as wheat, rice, barley, rye and oats.

It has potent anti-cancer properties, including the inhibition of tyrosine kinase proteins and inhibition of cell cycle at G2/M phase; it is also able to promote apoptosis by activation of caspase- 9 and $-3 .{ }^{5-7}$

Recently, clinical trials have confirmed the chemopreventive effects of genistein on many types of cancers. ${ }^{8-17}$

Many studies have been conducted on breast cancer demonstrating that genistein modulates oxidative stress, acting on estrogen receptor (ER) $\alpha / E R \beta$ ratio, ${ }^{18}$ 
down-regulates the activity of epidermal growth factor receptor (EGFR) and human epidermal growth factor receptor (HER)-2/neu modulating the expression levels of nuclear factor (NF)-kB ${ }^{19}$ and it inhibits protein phosphatase (PP2A), inducing growth reduction and apoptosis. ${ }^{20}$

However, genistein has a poor bioavailability in nature. It can be found as $\beta$-glucoside, which is hydrolized, in the small intestine, in the form of aglycones, ${ }^{21-23}$ its active pharmacological part.

During digestion, due to the action of microflora, the genistein is transformed in various metabolites. In this phase, the absorption efficiency is often reduced because the intestinal flora can degrade aglycones and produce aromatic acids.

It is known, however, that the glycosidic form can also be transported intact into the cell through a carrier and then hydrolyzed by cytosolic $\beta$-glucosidases. ${ }^{24-26}$

Shehata et al have fabricated self-emulsifying phospholipid pre-concentrates using some bioactive surfactants and they have demonstrated that they can be good nanocarriers for genistein, thereby overcoming its poor oral bioavailability. ${ }^{27}$

Meanwhile, Gavin et al studied a nanomocoadhesive system using lipid-based nanocarriers containing genistein, named nanoemulsions, and achieved excellent results in patients with oral cancer. ${ }^{28}$

This study suggests that in situ application of genistein in tumors could help in overcoming obstacles associated with its poor bioavailability. This may be simpler for oral cancer since they are present in an anatomical site of easier access.

There are not many studies in literature on the effects of genistein on oral cancer, except for some that studied its capacity to inhibit tyrosine kinases, ${ }^{29}$ in combination with other isoflavones, such as quercetin ${ }^{30,31}$ and biochanin A. ${ }^{32}$ Moreover, there are no studies that specifically investigate the effects of genistein on tongue squamous cell carcinoma.

For this reason, we evaluated in vitro anti-tumor action of genistein using 3 cell lines of OSCC; PE/CA-PJ15, PE/CA-PJ49 and HSC-3 cell lines.

Three concentrations of genistein have been used to assess adhesion, proliferation, migration, cell viability at 3 time points, and we calculated the $\mathrm{IC}_{50}$ values.

In addition, we studied the expression of OCT4 and survivin, 2 important proteins responsible for promoting tumorigenesis, after treatment with 20,50 and $100 \mu \mathrm{M}$ of genistein at 24, 48 and 72 hours of treatment.

\section{Materials and methods}

\section{Cell culture and treatment}

PE/CA-PJ15, PE/CA-PJ49, HSC-3 are cell lines of tongue carcinoma (European Collection of Cell Cultures, ECACC) maintained at standard conditions of temperature and atmosphere $\left(37^{\circ} \mathrm{C}\right.$ and $5 \% \mathrm{CO}_{2}$, respectively) for all tests used. We have used DMEM culture medium with 4,500 $\mathrm{mg} / \mathrm{L}$ glucose for PE/CA-PJ15 and PE/CA-PJ49 cells and Roswell Park Memorial Institute 1640 medium (RPMI 1640) for HSC-3 cells (Life Technologies, Gibco, Grand Island, NY, USA). Both culture media were supplemented with $10 \%$ fetal bovine serum, L-glutamine (2 mM) and penicillin-streptomycin (100 U/mL) (Sigma Aldrich, Saint Louis, MO, USA). Genistein (Abcam, Cambridge, UK) was dissolved in dimethylsulfoxide (DMSO) at a stock concentration of $5 \mathrm{mM}$ and serial dilutions of 20,50 and $100 \mu \mathrm{M}$ of genistein were prepared. The cell lines were treated for 24, 48 and 72 hours.

\section{xCELLigence real-time cell analyzers}

PE/CA-PJ15, PE/CA-PJ49, HSC-3 cells were resuspended in culture medium and then seeded, in triplicate, inside an E-plate of xCELLigence RTCA DP system (ACEA Biosciences Inc., San Diego, CA, USA). Genistein at concentrations of 20,50 and $100 \mu \mathrm{M}$ were added to cells in adhesion phase and the cells were monitored for 24,48 and 72 hours. To evaluate its effects on cell adhesion, genistein was added to cells after their adhesion phase. Control cells were treated with equivalent volume of the vehicle of genistein; DMSO. The concentrations used were the same as indicated previously. Moreover, the same concentrations of genistein were added in the proliferation phase to evaluate the effects of this nutraceutical on cellular proliferation. xCELLigence system measured the impedances parameter called "Cell Index (CI)" and hence we calculated also $\mathrm{IC}_{50}$ values at 24, 48 and 72 hours. The measurement of the $\mathrm{IC}_{50}$ values was performed by the instrument as described in the literature, with a high reliability. ${ }^{33,34}$ They were expressed as the mean $(M) \pm$ standard error of the mean $(\mathrm{SEM})(\mathrm{n}=3)$.

\section{MTT assay and Trypan blue exclusion test} Vybrant ${ }^{\circledR}$ MTT Cell Proliferation Assay Kit (Thermo Fisher Scientific, Waltham, MA, USA) was used to evaluate cell viability of PE/CA-PJ15, PE/CA-PJ49, and HSC-3 cells after treatments with genistein. We seeded $5 \times 10^{4}$ cells in a total volume of $250 \mu \mathrm{L} /$ well in a 96-well plate with 20 , 50 and $100 \mu \mathrm{M}$ of genistein for 24,48 and 72 hours. Then, $100 \mu \mathrm{L}$ of fresh culture medium and $10 \mu \mathrm{L}$ of $12 \mathrm{mM}$ MTT stock solution were added to each well after we had incubated the cells for 4 hours at $37^{\circ} \mathrm{C}$. To each well, SDS-HCl solution ( $10 \mathrm{~mL}$ of $0.01 \mathrm{M} \mathrm{HCl}$ to $1 \mathrm{gm}$ of SDS) was added for an incubation period of 12 hours in a humidified chamber at $37^{\circ} \mathrm{C}$. The absorbance was read at $570 \mathrm{~nm}$ using the 
Multiskan $^{\mathrm{TM}}$ GO Microplate Spectrophotometer (Thermo Fisher Scientific).

While PE/CA-PJ15, PE/CA-PJ49, HSC-3 cells were treated with genistein at the same concentrations and time points, Trypan blue exclusion method was used to validate the cell viability results obtained with MTT assay. A suspension of each cell line was mixed with $0.4 \%$ Trypan blue solution and, after 10 minutes, cells were counted automatically with

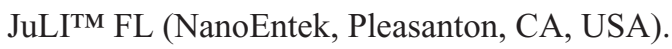

\section{Scratch assay}

A monolayer of each cell line was scraped with a p200 pipette tip and then washed twice with Dulbecco's phosphate buffered saline 1X (Life Technologies, Gibco) in order to remove debris. Then, cells were treated with the $\mathrm{IC}_{50}$ dose of genistein at 24 hours. Untreated cells were used as control. Initially, we acquired the first image (T0) and then the subsequent ones after 1 hour (T1), 2 hours (T2), 3 hours (T3), 5 hours (T4), 6 hours (T5) and 24 hours (T6) after treatment. ImageJ software (National Institutes of Health, Bethesda, MD, USA) was used to calculate the size of wound and analyze all the acquired images. GraphPad Prism 7 (GraphPad Software, Inc., CA, USA) software was used for statistical evaluation.

\section{Western blotting analysis}

After treatments with genistein at the same concentrations and time points previously used, cells were lysated to obtain proteins. They were measured and, then, separated by $15 \%$ SDS polyacrylamide gel electrophoresis and transferred to a nitrocellulose membrane (Bio-Rad, Hercules, CA, USA). Bovine serum albumin (BSA) 5\% was used for 1 hour as blocking solution.

Membranes were incubated with vitronectin (1:150; BD Biosciences), OCT4 (1:700; Novus Biologicals, Littleton, CO, USA), survivin (1:1,000; Cell Signaling Technology Inc., Danvers, MA, USA), and $\beta$-actin (1:5,000; Sigma Aldrich), overnight at $4^{\circ} \mathrm{C}$.

Then, peroxidase-conjugated secondary antibody was used (1:2,500; Santa Cruz Biotechnology, Dallas, TX, USA). Signals were acquired with enhanced chemiluminescence kit (ClarityTM Western ECL Substrate, Bio-Rad). UVP ChemiDoc-It ${ }^{\circledR}$ TS2 Imaging System (Analytik Jena AG, Jena, Germany) was used.

\section{Statistical analysis}

GraphPad Prism 7 software was used for Student's $t$-test and one-way analysis of variance (ANOVA) and all data were expressed as the $\mathrm{M} \pm \mathrm{SEM} ;{ }^{17}$ a $P$-values $<0.05, P<0.01$, $P<0.001$ were accepted as statistically significant.

\section{Results Effects of genistein on cell adhesion}

PE/CA-PJ15, PE/CA-PJ49 and HSC-3 cell lines were treated with 20,50 and $100 \mu \mathrm{M}$ of genistein during cell adhesion phase. Through xCELLigence system, we monitored adhesion kinetics in real time of the treated cells, using untreated cells as control. After 24, 48 and 72 hours, the CI values were taken and adhesion curves were analyzed. Data obtained show clear effects of genistein on all cells used even at 24 hours after the treatment.

The CI values showed that the adhesion of HSC-3 treated with $20 \mu \mathrm{M}$ of genistein appears to have reduced by $50 \%$ compared with the same untreated cells (Figure $1 \mathrm{~A}$ and $\mathrm{B})$. This reduction is evident at all time points considered, while, the values of CI of HSC-3 treated with $100 \mu \mathrm{M}$ of genistein after 48 and 72 hours are negative (Figure 1A and B).

PE/CA-PJ15 cell adhesion was reduced by $\sim 50 \%$, following treatment with concentrations of genistein ranging between 50 and $100 \mu \mathrm{M}, 24$ and 48 hours after the treatment. However, for longer treatments, such as 72 hours, even $50 \mu \mathrm{M}$ of genistein caused a halving of cell adhesion, compared with the untreated control (Figure 1C and D).

Cell adhesion of the PE/CA-PJ49 showed a reduction of about $50 \%$ when treated with an intermediate concentration between 20 and $50 \mu \mathrm{M}$ of genistein, at all time points (Figure 1E and F). Furthermore, the values of CI of $\mathrm{PE} / \mathrm{CA}-\mathrm{PJ} 49$ treated with $100 \mu \mathrm{M}$ of genistein were negative (Figure 1E and F).

To evaluate the effects of genistein on cell adhesion of tongue carcinoma cells, we also studied the expression levels of the vitronectin protein. It is a glycoprotein found mainly in the extracellular matrix and promotes cell adhesion and spreading. From the Western blotting performed on protein lysates of the 3 cell types used, we noticed that the expression of vitronectin seems to have decreased as a result of treatments with increasing concentrations of genistein, especially those long-lasting. In fact, at 48 hours after treatment with $100 \mu \mathrm{M}$ of genistein, vitronectin seems to be little expressed and almost unexpressed for treatments with 50 and $100 \mu \mathrm{M}$ of genistein at 72 hours (Figure 2A and B).

\section{Variation on cell proliferation and $\mathrm{IC}_{50}$ determination}

Genistein was added to all cancer cell lines in the cell proliferation phase. All cells were monitored in real time and all cell index values were taken at 24, 48 and 72 hours. In addition, they were converted into percentage values and we 
A

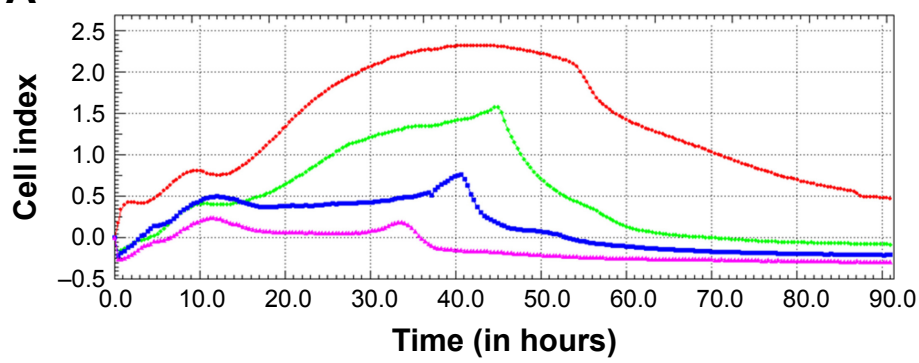

C

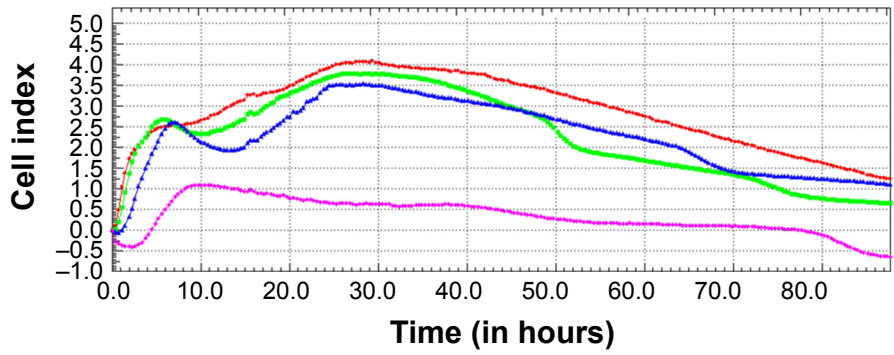

E

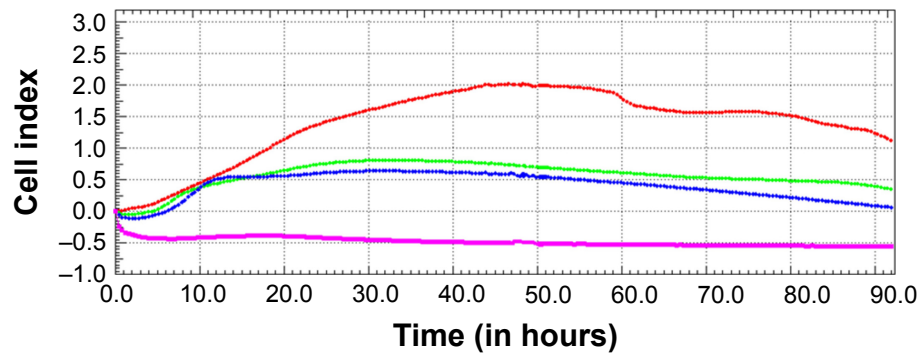

n Control $\square 20 \mu \mathrm{M} \quad 50 \mu \mathrm{M} \quad 100 \mu \mathrm{M}$
B HSC-3

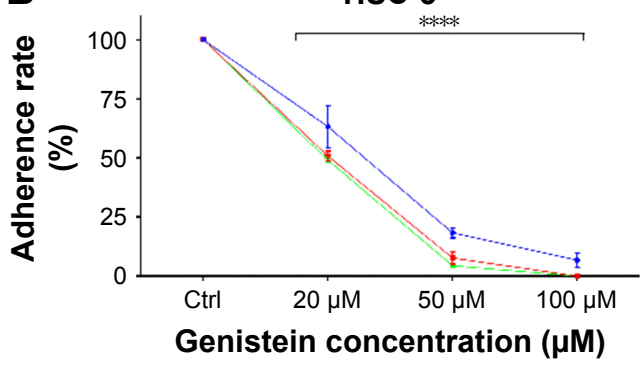

D
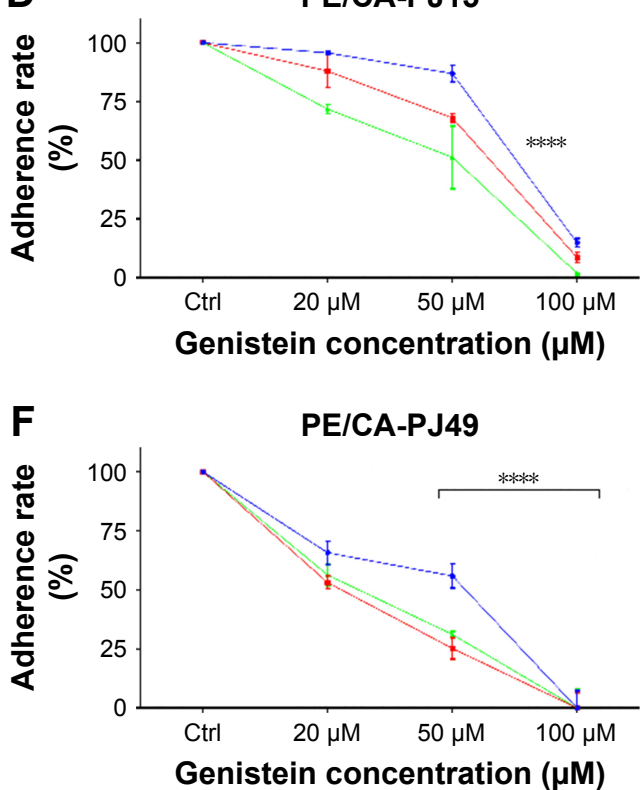

Genistein concentration $(\mu \mathrm{M})$

Figure I Genistein inhibited adhesion of tongue cancer cells.

Notes: All cell lines were treated with 20,50 and $100 \mu \mathrm{M}$ of genistein. In the graphs, there is an initial phase of cell adhesion, followed by a plateau phase prior to a gradual period of proliferation. The adhesion of (A) HSC-3 cells, (C) PE/CA-PJI5 cells and (E) PE/CA-PJ49 cells is shown. Untreated cells were used as control (red curves). We monitored in real time the adhesion for 24, 48 and 72 hours after treatment and all cell index values of HSC-3 cells (B), PE/CA-PJI5 cells (D) and PE/CA-PJ49 cells (F). The results are the mean $\mathrm{Cl}$ for 3 replicates $\pm \mathrm{SD}$. $* * * * P<0.0001$.

A

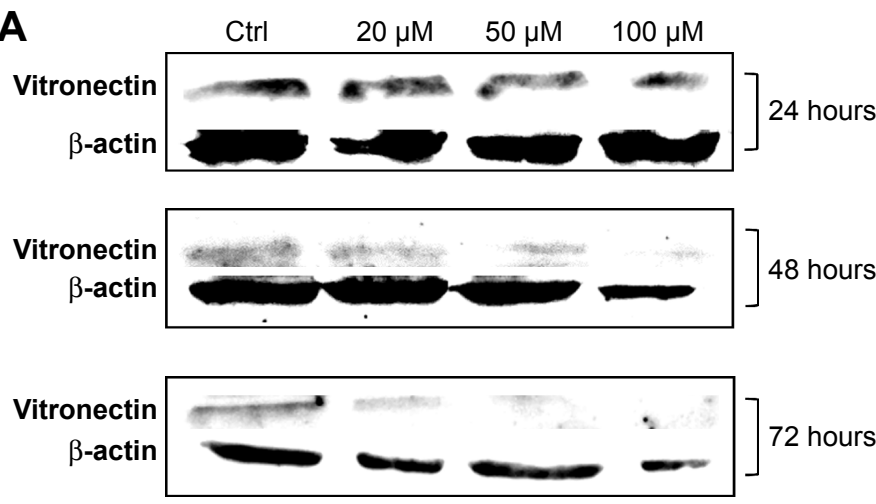

B

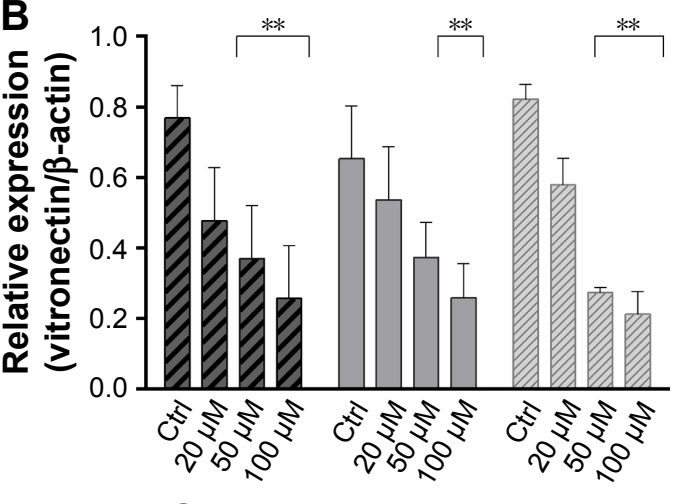

Genistein concentration $(\mu \mathrm{M})$

Figure 2 Inhibition of vitronectin expression.

Notes: Western blotting shows the inhibition of vitronectin expression after genistein treatment. Vitronectin is especially down-regulated at 48 hours with $100 \mu M$ of genistein and at 72 hours with 50 and $100 \mu \mathrm{M}$ of genistein $(\mathbf{A})$. Also shown is significance degree of tests used $* * P<0.005(\mathbf{B})$

Abbreviation: Ctrl, control. 
used the ANOVA as the statistical test to evaluate the cell proliferation percentage.

We found a $50 \%$ significant reduction of cell proliferation for all cells treated with $20 \mu \mathrm{M}$ of genistein after 24 hours of treatment (Figure 3A); while, the same reduction was found at 48 hours in a concentration range between 20 and $50 \mu \mathrm{M}$ of genistein (Figure 3B). Instead, cell proliferation seems to be reduced by $50 \%$ compared to the control at 72 hours in all cells treated with $50 \mu \mathrm{M}$ of genistein (Figure 3C). In all cell lines, $100 \mu \mathrm{M}$ of genistein resulted in a reduction of about $25 \%$ of proliferation at all time points considered. All the data were considered statistically significant for $P<0.005$, $P<0.001, P<0.0001$ (Figure 3A-C).

From the growth curves obtained by treating cells with 20,50 and $100 \mu \mathrm{M}$ of genistein, CI values were used to calculate the value of $\mathrm{IC}_{50}$ at 24,48 and 72 hours. In particular, it was found that at 24 hours, the $\mathrm{IC}_{50}$ value was approximately $46 \mu \mathrm{M}$ for all cell lines used (Figure 4A-F); while for treatments at 48 hours, the average $\mathrm{IC}_{50}$ value of the 3 cell lines used was approximately $40 \mu \mathrm{M}$ (Figure $4 \mathrm{~A}-\mathrm{F}$ ). However, there was a slight discrepancy between the lines for 72-hour treatments. In fact, for HSC-3 and PE/CA-PJ15 the $\mathrm{IC}_{50}$ value seemed to be around $22 \mu \mathrm{M}$ (Figure 4A-D). Only for PE/CA-PJ49, this value was around $46 \mu \mathrm{M}$. This was probably because this line showed a higher resistance to treatment with genistein than the other (Figure 4D and E).

\section{Effects of genistein on cell viability}

For a better evaluation of genistein on cell viability, we used 2 simple tests: the MTT assay and the Trypan blue assay. In both assays, we noticed that genistein changed cell viability even 24 hours after treatment.

In fact, we noticed a reduction of about $50 \%$ of cell viability in each treated cell line with concentrations between 20 and $50 \mu \mathrm{M}$ at 24, 48 and 72 hours (Figure 5A). Trypan blue assay confirmed almost all the data obtained with the MTT
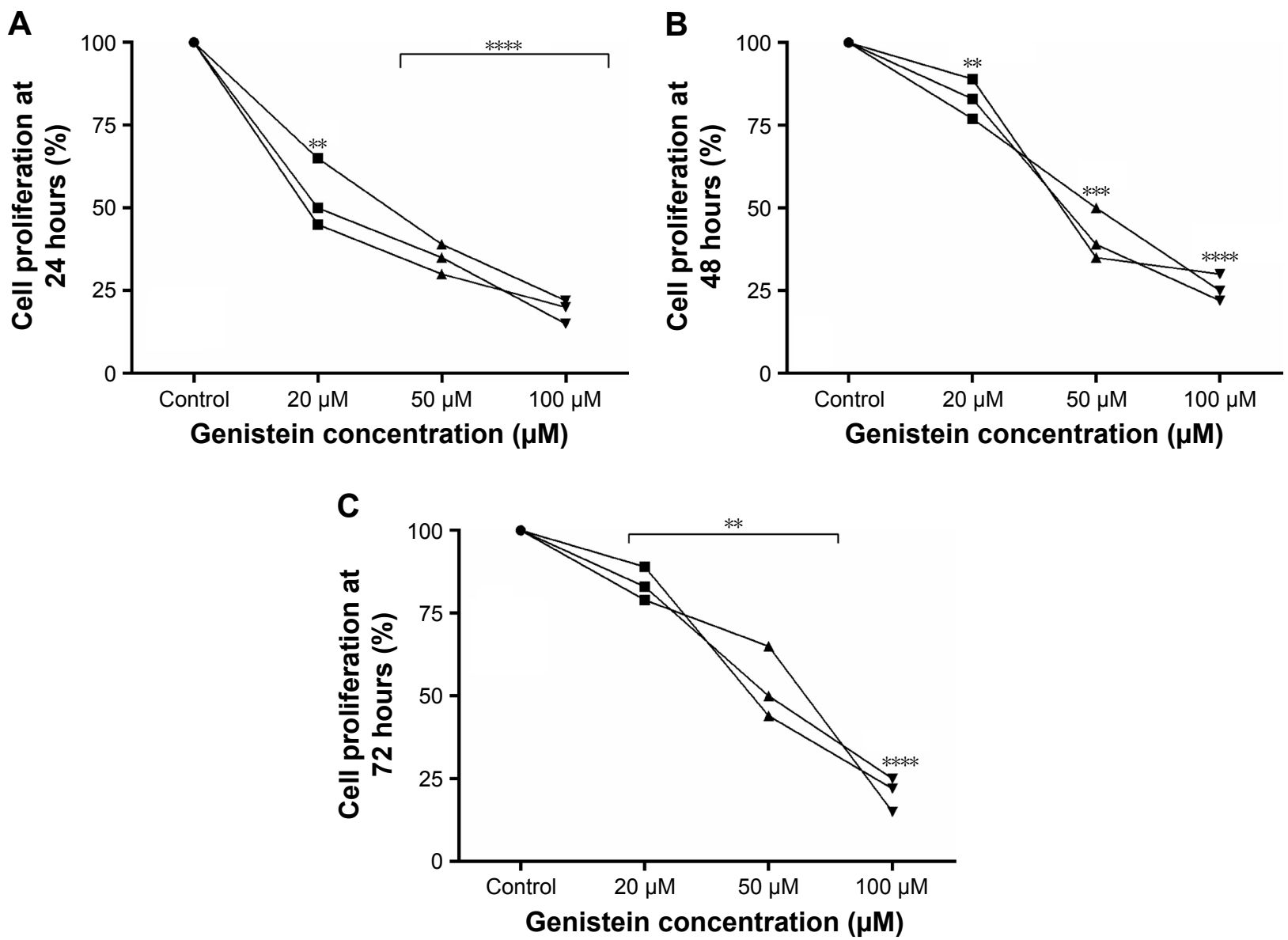

Figure 3 Variation in cell proliferation rate (\%).

Notes: Cell index $(\mathrm{Cl})$ values were measured and converted to percentage rate using untreated cells as control (I00\% adhesion). (A) This shows a $50 \%$ reduction of adhesion posttreatment with $20 \mu \mathrm{M}$ genistein at 24 hours. (B) The same reduction is present for treatment between 20 and $50 \mu \mathrm{M}$ of genistein at 48 hours, and for $50 \mu \mathrm{M}$ of genistein at 72 hours (C). Also shown is significance degree of tests used $(* * P<0.005, * * * P<0.00$ I, $* * * * P<0.000 I)$. 


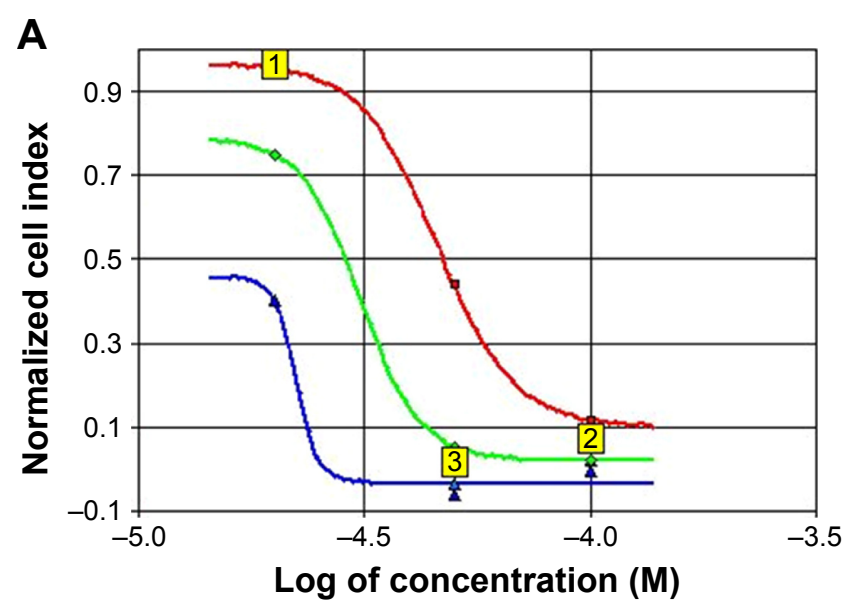

B
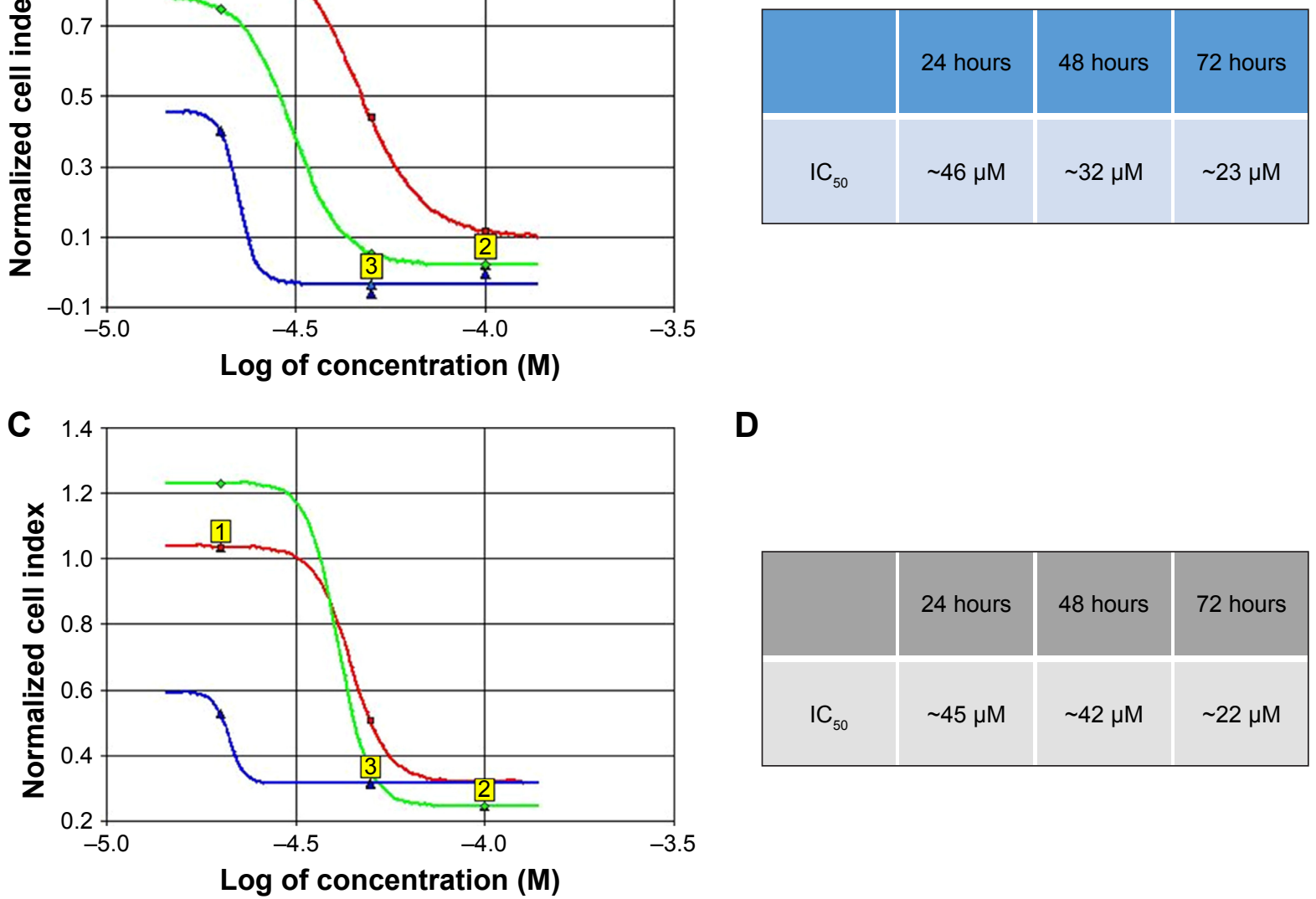

D
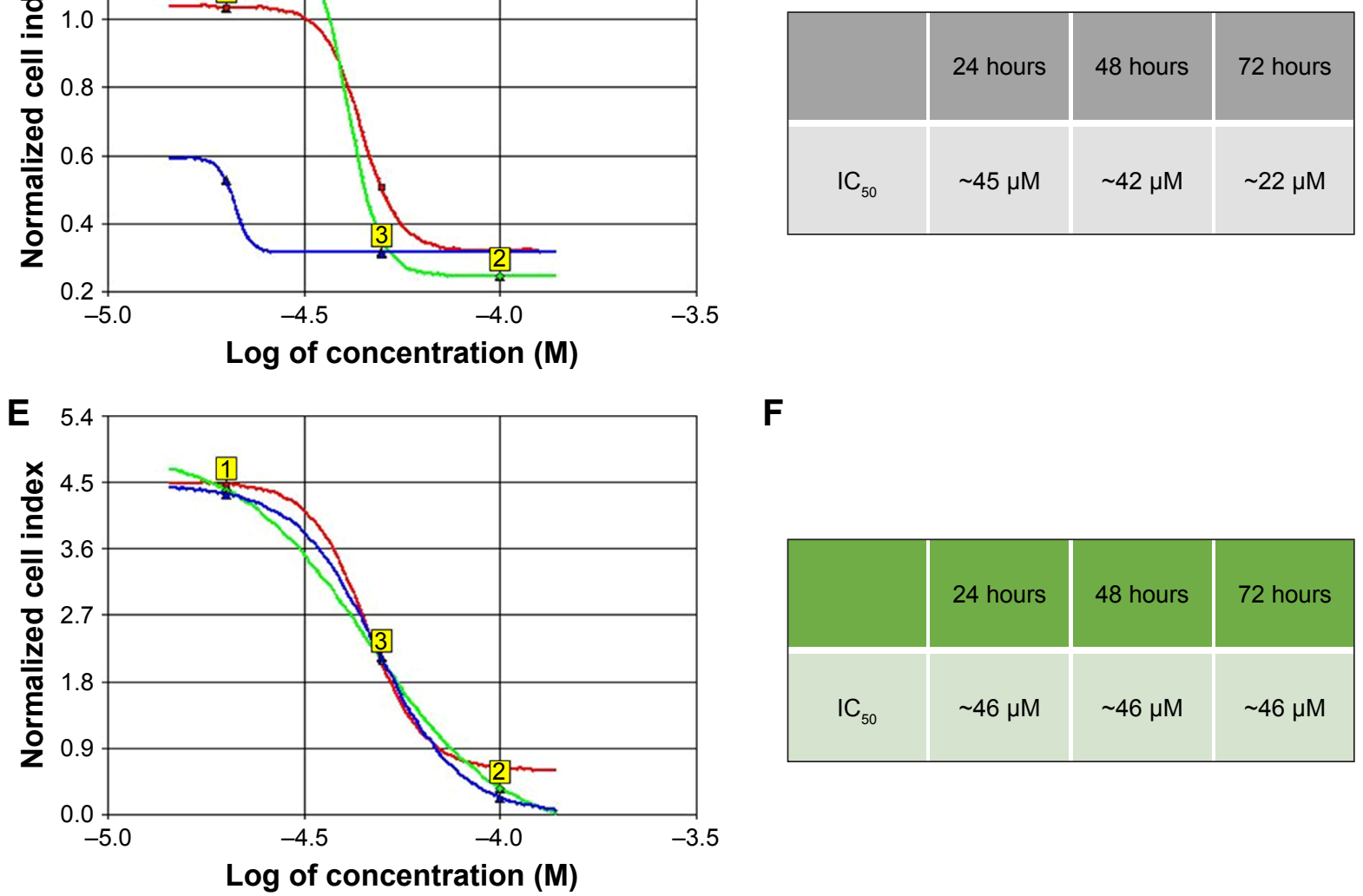

$\mathbf{F}$

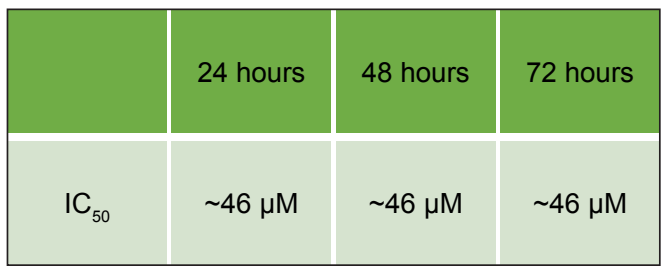

Figure $4 I_{50}$ values.

Notes: Dose-response curves are shown for HSC-3 cells (A), PE/CA-PJI 5 cells (C) and PE/CA-PJ49 cells (E). In each graph, the yellow square with the numbers I, 2 and 3 indicates, respectively, $I C_{50}$ values at 24,48 and 72 hours. $I C_{50}$ values are expressed as the mean $(M) \pm$ standard error of the mean ( $\left.n=3\right)$ and they are shown as the average of all IC $\mathrm{IC}_{50}$ values of HSC-3 cells (B), PE/CA-PJI5 cells (D), PE/CA-PJ49 cells (F) at each time point. $R^{2}$ of IC ${ }_{50}$ was 0.99.

assay (Figure 5B). All the data were considered statistically significant for $P<0.001$ and $P<0.0001$.

\section{Determination of cell migration rate}

To evaluate if genistein is able to reduce the migration of the tongue cancer cells, we used the Scratch assay. Tongue cells were treated with $\mathrm{IC}_{50}$ at 24 hours, previously calculated. The control had not undergone any treatment.

The treated cells migrated very little in the cut area (Figure 6A). The most significant effects were evident starting from $\mathrm{T} 4$ and, specifically, the wound of treated cells does not show any healing after 24 hours (Figure 6A). 


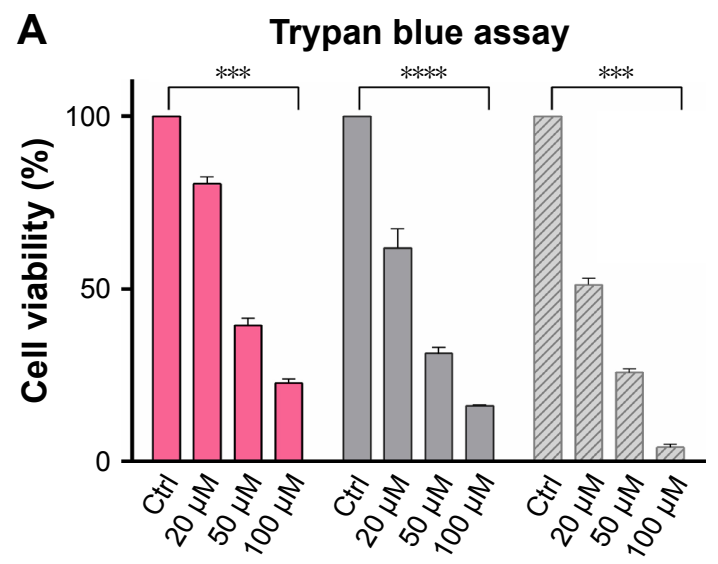

Genistein concentration $(\mu \mathrm{M})$

24 hours $\square 48$ hours $\square 72$ hours
B

MTT assay

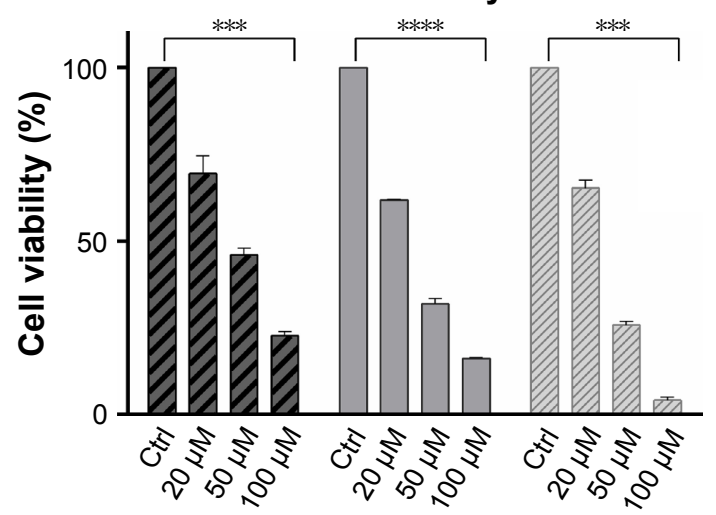

Genistein concentration $(\mu \mathrm{M})$

Z24 hours $\square 48$ hours $\square 72$ hours

Figure $\mathbf{5}$ Genistein reduces the viability of tongue cancer cells.

Notes: Trypan blue test $(\mathbf{A})$ and MTT assay $(\mathbf{B})$ show a proportional reduction in cell viability with increasing concentrations of genistein. Experiments were performed at least 3 times and results are presented as the mean $\pm \mathrm{SD}$, and are statistically significant for $* * * P<0.00 \mathrm{I}$ and $* * * * P<0.000$ I.

Abbreviation: Ctrl, control.

The untreated control showed an increasing level of healing of the wound during the considered times total healing after 24 hours (Figure 6A).

Evaluations of the timing at T4, T5 and T6 were most significant with $P$-value $<0.05, P<0.01, P<0.001$ (Figure 6B).

\section{Effects of genistein on tumorigenesis}

After treating cancer cells of the tongue with different concentrations of genistein, we evaluated the expression of OCT4 and survivin. OCT4 is a known protein because its overexpression promotes tumorigenesis in different types of cells. In tongue
A
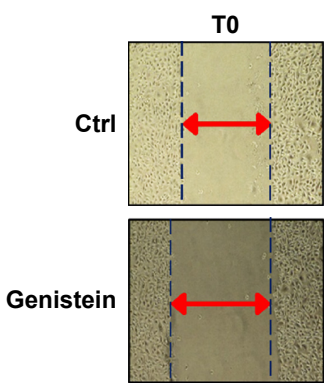

T0=0 hour
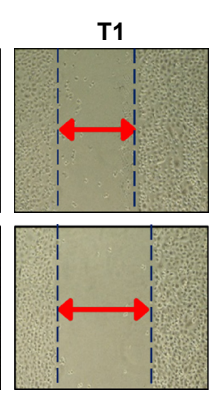

T1=1 hour
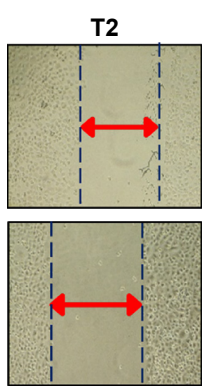

T2=2 hours
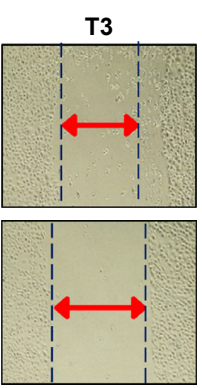

T3=3 hours
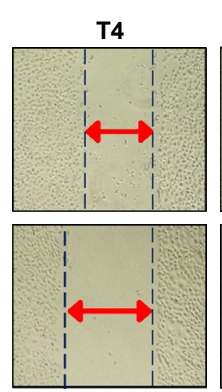

T4=5 hours

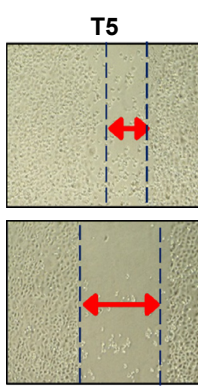

$\mathrm{T} 5=6$ hours

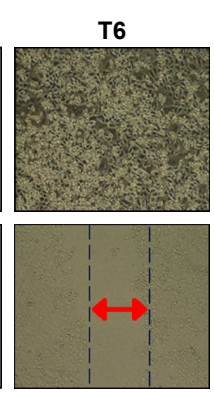

T6=24 hours
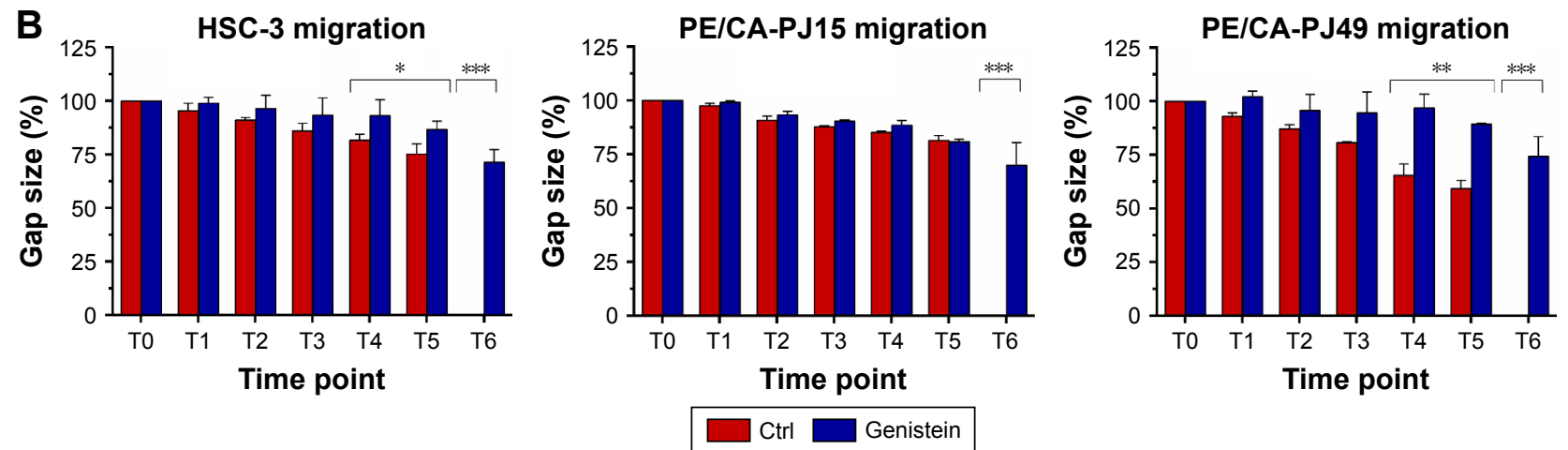

Figure 6 Effects of genistein on cell migration.

Notes: Significant increase of the gap size is more evident from T4 in tongue carcinoma cells compared to untreated control (Ctrl) (A). All experiments were performed at least 3 times and results are presented as the mean $\pm S D$. $* P<0.05, * * P<0.0$ l, $* * * P<0.001$ (B). 


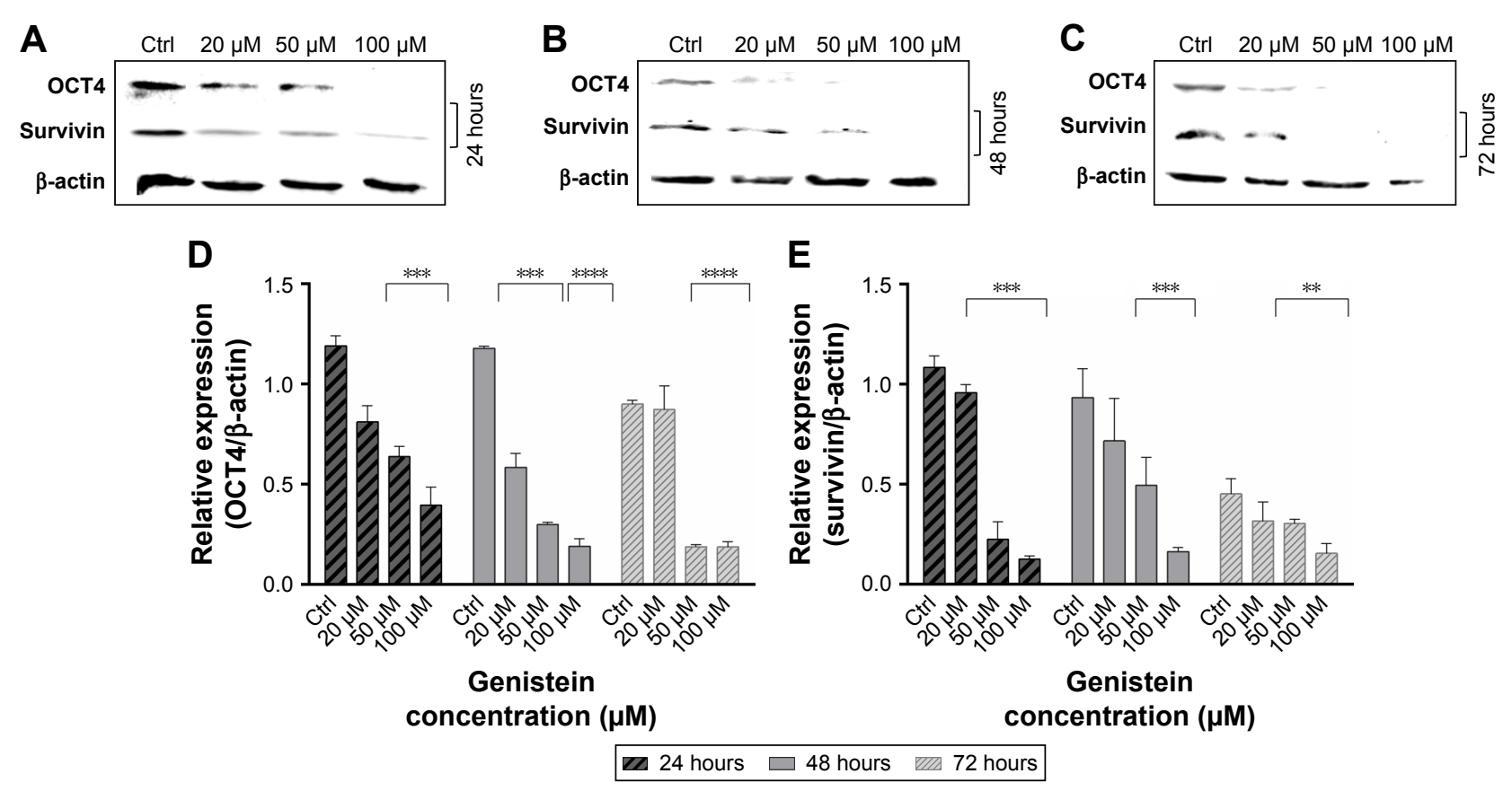

Figure 7 Genistein reduces tumorigenesis and promotes apoptosis.

Notes: Variation in level of expression of OCT4 and survivin. Genistein inhibits survivin and OCT4 at all time points considered (A-C). The significance degree of tests used is **p $<0.005$, *** $p<0.001$, ***** $<0.000$ I (D-E)

Abbreviation: Ctrl, control.

cancer cells, genistein appears to have an action on the expression of OCT4 only after high concentration treatments.

In fact, Figure 7 shows a reduction in those cells that were treated with 50 and $100 \mu \mathrm{M}$ of genistein for each time point considered.

Moreover, expression of survivin appears to be extremely reduced as a result of treatments with concentrations of 50 and $100 \mu \mathrm{M}$ at 24 hours (Figure 7A and E). This seems to be confirmed at all time points considered, and especially at a concentration of $100 \mu \mathrm{M}$, there is almost a complete inhibition (Figure 7A-E).

\section{Discussion}

Modern treatment protocols of OSCC did not lead to great results despite adoption of new surgical techniques and innovative chemotherapy formulations.

In recent years, the scientific community has been fascinated by the remarkable properties that natural substances possess, especially by many features that make them anticancer substances.

Genistein is an isoflavone isolated in 1899 from dyeing of genistra, characterized in 1926 and synthesized for the first time in 1928. It is well known to be present mainly in soybeans. It has a structure similar to estrogen and this characteristic seems to play an important role to help improve menopause symptoms. ${ }^{35}$
Notable are also its anti-tumor effects, demonstrated especially in breast cancer ${ }^{20,36-38}$ and prostate cancer. ${ }^{39-41}$

Even for OSCC, there are studies on genistein action, but they investigate the inhibitory activity of the protein tyrosine kinase, ${ }^{29}$ its action on tumor angiogenesis ${ }^{42}$ and its chemopreventive effects when used with quercetin ${ }^{30,31}$ and biochanin $\mathrm{A},{ }^{32}$ which are other isoflavones.

Park et al have carried out an in vitro study on oral cancer cells, HSC-3 and KB, validating their results on nude mice. They demonstrated that genistein and cetuximab have a synergistic action in the inhibition of EGFR signaling pathway. ${ }^{43}$

In literature, there are no papers that demonstrate the effects of genistein, as the only treatment against tongue carcinoma, which is considered the most common oral cancer and the most aggressive of all oral cancers.

Therefore, we studied the effects of this isoflavone on 3 lines of squamous cell carcinoma of the tongue; HSC 3, PE/ CA-PJ15 and PE/CA-PJ49 cell lines.

We treated the cells with 3 concentrations of genistein; 20,50 and $100 \mu \mathrm{M}$. The choice of concentrations was made by studying the literature data and, in particular, inspired by the work of Johnson et al. Even when the genistein was used with the biochanin A, the results on oral carcinoma cells were good. All in vitro assessments were made considering 3 time points; 24, 48 and 72 hours. 
In this paper, our goal was to show how genistein inhibits adhesion, proliferation, viability and migration of cancer cells of the tongue.

It is known that alterations in cell adhesion affect the ability of cells to move. In particular, cancer cells need to be able to move and migrate in order to spread, and cell adhesion plays an important role in regulating cell movements and the spread of metastases. ${ }^{44}$

Our data show that cell adhesion is decreased by almost $50 \%$ at concentrations between 20 and $50 \mu \mathrm{M}$, at 24 hours, in almost all cell types used compared with untreated cells. This decrease was confirmed at other time points within the range of the concentrations used.

This showed that the adhesion of the tongue cancer cells is greatly compromised by treatment with genistein.

Kingsley et al have shown that the adhesion of cells of OSCC (CAL 27 and SCC25 cell lines) was clearly decreased when cells were treated with soy protein extract ${ }^{45}$ belonging to different isoflavones, including genistein. ${ }^{46}$

In addition, to confirm the strong action of genistein on adhesion, we also evaluated the expression of vitronectin, a well known adhesion protein. Western blotting analysis demonstrates that the inhibition of the vitronectin after treatment with genistein is dose-dependent and is also down-regulated by treatment at 48 and 72 hours with high concentrations $(50-100 \mu \mathrm{M})$.

Inhibitory effects of genistein are also confirmed by Skogseth et al. They demonstrate that genistein is able to reduce the adhesion of prostate cancer cells because it inhibits many adhesion proteins. This is probably because it is a strong inhibitor of tyrosine kinases. ${ }^{47}$

Even for Haier et al, genistein has strong cell adhesion inhibition capacity in colon carcinoma cells. Indeed, it also seems to inhibit the expression of vitronectin in HT-29 cell lines. ${ }^{48}$

In our study, we also evaluated the effects of genistein on cell proliferation. Also, in this case, we obtained a strong reduction of proliferation with high significance $(P<0.0001)$ for all tongue cancer cells treated with concentrations between 20 and $50 \mu \mathrm{M}$ at all time points.

Davis et al showed that genistein also has anti-proliferative action on prostate tumor cells. ${ }^{49}$ Alhasan et al confirmed that genistein has a strong anti-proliferative effect in OSCC HN4 cell line treated with $50 \mu \mathrm{M}$ of genistein, even favoring an arrest of the cell cycle and promotion of apoptosis. ${ }^{50}$

In addition, we used the CI values obtained with the $\mathrm{xCELLigence} \mathrm{system} \mathrm{to} \mathrm{calculate} \mathrm{the} \mathrm{IC}_{50}$ values of genistein at 24,48 and 72 hours.
In all cell lines, on average, we found $\mathrm{IC}_{50}$ values of approximately $46 \mu \mathrm{M}$ at 24 hours and approximately $40 \mu \mathrm{M}$ at 48 hours. However, we obtained discordant $\mathrm{IC}_{50}$ values at 72 hours in each cell line used. This was probably because PE/CA-PJ49 cells are more aggressive than the other 2 cell lines used.

Johnson et al affirm that the $\mathrm{IC}_{50}$ value for the $\mathrm{SCC} 15$ and SCC 25 cell lines, OSCC cells, is $\sim 50 \mu \mathrm{M} .{ }^{32}$ The same $\mathrm{IC}_{50}$ value was attributed to the breast cancer cells. ${ }^{51}$

In addition, we showed that tongue carcinoma cells' viability decreased by $50 \%$ when treated with concentrations between 20 and $50 \mu \mathrm{M}$ of genistein, almost at all time points.

Alhasan et al have reported a significant reduction of the vitality and growth of OSCC cells after treatment with genistein. ${ }^{50}$ Ye et al also argued that genistein inhibits the viability and proliferation of cells of head and neck cancer by also inducing apoptosis. ${ }^{52}$

In our opinion, one of the most significant results, among those obtained, relates to cell migration. In fact, the treatment of all cells with the $\mathrm{IC}_{50}$ value of genistein at 24 hours showed a very significant reduction of cell migration after 24 hours; $P<0.001$. This shows that genistein can inhibit tongue carcinoma cells migration and so it can have a big effect on the inhibition of the metastasis processes.

This power of genistein seems to be confirmed for ovarian cancer $^{53}$ and OSCC. ${ }^{42}$

Finally, we have shown that genistein is able to strongly inhibit, with treatment $>50 \mu \mathrm{M}$, the expression of OCT4 and survivin in tongue cancer cells, thus reducing the tumorigenesis enough to be considered a good agent against this kind of tumor.

This inhibitory action of OCT4 expression seems to be also confirmed in embryonal carcinoma, ${ }^{54}$ while Tian et al have shown that genistein down-regulates the expression of survivin in H446 small-cell lung cancer cells. ${ }^{55}$

\section{Conclusion}

Genistein is a natural isoflavone whose effects have been studied fully in many neoplastic diseases.

However, its anti-tumor properties were evaluated, especially in combination with other isoflavones, against OSCC and there are no data in literature that make clear its effect, in particular on tongue carcinoma. There are several studies on the use of genistein for other cancers, very few on oral cancer and almost no specific study on tongue squamous cell carcinoma.

With this in vitro study, we can confirm that genistein acts on the tongue cancer cells by inhibiting efficaciously cell viability, proliferation, adhesion and migration. 
This shows that genistein has excellent anti-cancer properties that can be explored for this type of tumor.

However, in vivo studies are needed to further validate these results and develop a suitable delivery system that acts directly in situ to overcome the problems concerning the bioavailability.

\section{Author contributions}

Dr FA designed the paper, collected data, drafted the manuscript, drew the figures and approved the final manuscript as submitted. Dr GT, Dr AC and Dr DP did statistical analysis with the data collected. Dr MRP drafted the initial manuscript with Dr FA and approved the final manuscript as submitted. Prof LLM coordinated and supervised data collection, critically reviewed the manuscript, and approved the final manuscript as submitted. All authors contributed toward data analysis, drafting and revising the paper and agree to be accountable for all aspects of the work.

\section{Disclosure}

The authors report no conflicts of interest in this work.

\section{References}

1. Lau A, Li KY, Yang WF, Su YX. Induction chemotherapy for squamous cell carcinomas of the oral cavity: a cumulative meta-analysis. Oral Oncol. 2016;61:104-114.

2. Adkins D, Ley J, Michel L, et al. nab-Paclitaxel, cisplatin, and 5-fluorouracil followed by concurrent cisplatin and radiation for head and neck squamous cell carcinoma. Oral Oncol. 2016;61:1-7.

3. Sahu N, Grandis JR. New advances in molecular approaches to head and neck squamous cell carcinoma. Anticancer Drugs. 2011;22(7): 656-664.

4. Russo M, Russo GL, Daglia M, et al. Understanding genistein in cancer: the "good" and the "bad" effects: a review. Food Chem. 2016; 196:589-600.

5. Banerjee S, Li Y, Wang Z, Sarkar FH. Multi-targeted therapy of cancer by genistein. Cancer Lett. 2008;269(2):226-242.

6. Spinozzi F, Pagliacci MC, Migliorati G, et al. The natural tyrosine kinase inhibitor genistein produces cell cycle arrest and apoptosis in Jurkat T-leukemia cells. Leuk Res. 1994;18(6):431-439.

7. Yamasaki M, Mine Y, Nishimura M, et al. Genistein induces apoptotic cell death associated with inhibition of the NF-kappaB pathway in adult T-cell leukemia cells. Cell Biol Int. 2013;37(7):742-747.

8. Roh T, Kim SW, Moon SH, Nam MJ. Genistein induces apoptosis by down-regulating thioredoxin-1 in human hepatocellular carcinoma SNU-449 cells. Food Chem Toxicol. 2016;97:127-134.

9. Yang Y, Zang A, Jia Y, et al. Genistein inhibits A549 human lung cancer cell proliferation via miR-27a and MET signaling. Oncol Lett. 2016;12(3):2189-2193.

10. Yang YM, Yang Y, Dai WW, Li XM, Ma JQ, Tang LP. Genistein-induced apoptosis is mediated by endoplasmic reticulum stress in cervical cancer cells. Eur Rev Med Pharmacol Sci. 2016;20(15):3292-3296.

11. Ahn JC, Biswas R, Chung PS. Combination with genistein enhances the efficacy of photodynamic therapy against human anaplastic thyroid cancer cells. Lasers Surg Med. 2012;44(10):840-849.

12. Lazarevic B, Boezelijn G, Diep LM, et al. Efficacy and safety of shortterm genistein intervention in patients with localized prostate cancer prior to radical prostatectomy: a randomized, placebo-controlled, doubleblind Phase 2 clinical trial. Nutr Cancer. 2011;63(6):889-898.
13. Atefeh Z, Vahid C, Hasan N, Saeed A, Mahnaz H. Combination treatment of glioblastoma by low-dose radiation and genistein. Curr Radiopharm. 2016;9(3):258-263.

14. Khaw AK, Yong JW, Kalthur G, Hande M. Genistein induces growth arrest and suppresses telomerase activity in brain tumor cells. Genes Chromosomes Cancer. 2012;51(10):961-974.

15. Suzuki R, Kang Y, Li X, Roife D, Zhang R, Fleming JB. Genistein potentiates the antitumor effect of 5-Fluorouracil by inducing apoptosis and autophagy in human pancreatic cancer cells. Anticancer Res. 2014;34(9):4685-4692.

16. Kim SH, Kim CW, Jeon SY, Go RE, Hwang KA, Choi KC. Chemopreventive and chemotherapeutic effects of genistein, a soy isoflavone, upon cancer development and progression in preclinical animal models. Lab Anim Res. 2014;30(4):143-150.

17. Van Cutsem E, Findlay M, Osterwalder B, et al. Capecitabine, an oral fluoropyrimidine carbamate with substantial activity in advanced colorectal cancer: results of a randomized phase II study. J Clin Oncol. 2000;18(6):1337-1345.

18. Nadal-Serrano M, Pons DG, Sastre-Serra J, Blanquer-Rosselló Mdel M, Roca P, Oliver J. Genistein modulates oxidative stress in breast cancer cell lines according to ERalpha/ERbeta ratio: effects on mitochondrial functionality, sirtuins, uncoupling protein 2 and antioxidant enzymes. Int J Biochem Cell Biol. 2013;45(9):2045-2051.

19. Valachovicova T, Slivova V, Bergman H, Shuherk J, Sliva D. Soy isoflavones suppress invasiveness of breast cancer cells by the inhibition of NF-kappaB/AP-1-dependent and -independent pathways. Int $J$ Oncol. 2004;25(5):1389-1395.

20. Zhao Q, Zhao M, Parris AB, Xing Y, Yang X. Genistein targets the cancerous inhibitor of PP2A to induce growth inhibition and apoptosis in breast cancer cells. Int J Oncol. 2016;49(3):1203-1210.

21. Mazur W. Phytoestrogen content in foods. Baillieres Clin Endocrinol Metab. 1998;12(4):729-742.

22. Cassidy A. Potential risks and benefits of phytoestrogen-rich diets. Int J Vitam Nutr Res. 2003;73(2):120-126.

23. Setchell KD, Brown NM, Desai P, et al. Bioavailability of pure isoflavones in healthy humans and analysis of commercial soy isoflavone supplements. J Nutr. 2001;131(4 Suppl):1362S-1375S.

24. Manach C, Scalbert A, Morand C, Rémésy C, Jiménez L. Polyphenols: food sources and bioavailability. Am J Clin Nutr. 2004;79(5): 727-747.

25. Walle T. Absorption and metabolism of flavonoids. Free Radic Biol Med. 2004;36(7):829-837.

26. Scalbert A, Williamson G. Dietary intake and bioavailability of polyphenols. J Nutr. 2000;130(8S Suppl):2073S-2085S.

27. Shehata EM, Elnaggar YS, Galal S, Abdallah OY. Self-emulsifying phospholipid pre-concentrates (SEPPs) for improved oral delivery of the anti-cancer genistein: development, appraisal and ex-vivo intestinal permeation. Int J Pharm. 2016;511(2):745-756.

28. Gavin A, Pham JT, Wang D, Brownlow B, Elbayoumi TA. Layered nanoemulsions as mucoadhesive buccal systems for controlled delivery of oral cancer therapeutics. Int J Nanomedicine. 2015;10:1569-1584.

29. Sugiura T, Shirasuna K, Hayashido Y, Sakai T, Matsuya T. Effects of human fibroblasts on invasiveness of oral cancer cells in vitro: isolation of a chemotactic factor from human fibroblasts. Int $J$ Cancer. 1996;68(6):774-781.

30. Browning AM, Walle UK, Walle T. Flavonoid glycosides inhibit oral cancer cell proliferation - role of cellular uptake and hydrolysis to the aglycones. J Pharm Pharmacol. 2005;57(8):1037-1042.

31. Walle T, Browning AM, Steed LL, Reed SG, Walle UK. Flavonoid glucosides are hydrolyzed and thus activated in the oral cavity in humans. J Nutr. 2005;135(1):48-52.

32. Johnson TL, Lai MB, Lai JC, Bhushan A. Inhibition of cell proliferation and MAP kinase and Akt pathways in oral squamous cell carcinoma by genistein and biochanin A. Evid Based Complement Alternat Med. 2010;7(3):351-358.

33. Pan $\mathrm{T}$, Khare $\mathrm{S}, \mathrm{Ackah} \mathrm{F}$, et al. In vitro cytotoxicity assessment based on $\mathrm{KC}(50)$ with real-time cell analyzer (RTCA) assay. Comput Biol Chem. 2013;47:113-120. 
34. Zhang M, Aguilera D, Das C, et al. Measuring cytotoxicity: a new perspective on LC50. Anticancer Res. 2007;27(1A):35-38.

35. Marini H, Minutoli L, Polito F, et al. Effects of the phytoestrogen genistein on bone metabolism in osteopenic postmenopausal women: a randomized trial. Ann Intern Med. 2007;146(12):839-847.

36. Avci CB, Susluer SY, Caglar HO, et al. Genistein-induced mir-23b expression inhibits the growth of breast cancer cells. Contemp Oncol (Pozn). 2015;19(1):32-35

37. Chen J, Duan Y, Zhang X, Ye Y, Ge B, Chen J. Genistein induces apoptosis by the inactivation of the IGF-1R/p-Akt signaling pathway in MCF-7 human breast cancer cells. Food Funct. 2015;6(3):995-1000.

38. Orlando L, Schiavone P, Cinieri S. Genistein: the future of prevention and treatment of breast cancer? Cancer Biol Ther. 2011;11(10):918-920.

39. Pavese JM, Krishna SN, Bergan RC. Genistein inhibits human prostate cancer cell detachment, invasion, and metastasis. Am J Clin Nutr. 2014;100(Suppl 1):431S-436S.

40. Chiyomaru T, Yamamura S, Fukuhara S, et al. Genistein inhibits prostate cancer cell growth by targeting miR-34a and oncogenic HOTAIR PLoS One. 2013;8(8):e70372.

41. Chiyomaru T, Yamamura S, Zaman MS, et al. Genistein suppresses prostate cancer growth through inhibition of oncogenic microRNA-151. PLoS One. 2012;7(8):e43812.

42. Myoung H, Hong SP, Yun PY, Lee JH, Kim MJ. Anti-cancer effect of genistein in oral squamous cell carcinoma with respect to angiogenesis and in vitro invasion. Cancer Sci. 2003;94(2):215-220.

43. Park SJ, Kim MJ, Kim YK, Kim SM, Park JY, Myoung H. Combined cetuximab and genistein treatment shows additive anti-cancer effect on oral squamous cell carcinoma. Cancer Lett. 2010;292(1):54-63.

44. Khalili AA, Ahmad MR. A review of cell adhesion studies for biomedical and biological applications. Int J Mol Sci. 2015;16(8):18149-18184.

45. Vainshtein JM, Samuels S, Tao Y, et al. Impact of xerostomia on dysphagia after chemotherapy-intensity-modulated radiotherapy for oropharyngeal cancer: prospective longitudinal study. Head Neck 2016;38(Suppl 1):E1605-E1612.
46. Kingsley K, Truong K, Low E, et al. Soy protein extract (SPE) exhibits differential in vitro cell proliferation effects in oral cancer and normal cell lines. J Diet Suppl. 2011;8(2):169-188.

47. Skogseth H, Holt RU, Larsson E, Halgunset J. Tyrosine kinase inhibitors alter adhesivity of prostatic cancer cells to extracellular matrix components. APMIS. 2006;114(3):225-233.

48. Haier J, Nasralla M, Nicolson GL. Influence of phosphotyrosine kinase inhibitors on adhesive properties of highly and poorly metastatic HT-29 colon carcinoma cells to collagen. Int J Colorectal Dis. 1999; 14(2):119-127.

49. Davis JN, Kucuk O, Sarkar FH. Expression of prostate-specific antigen is transcriptionally regulated by genistein in prostate cancer cells. Mol Carcinog. 2002;34(2):91-101.

50. Alhasan SA, Ensley JF, Sarkar FH. Genistein induced molecular changes in a squamous cell carcinoma of the head and neck cell line. Int J Oncol. 2000;16(2):333-338.

51. Scherbakov AM, Andreeva OE. Apigenin inhibits growth of breast cancer cells: the role of ERalpha and HER2/neu. Acta Naturae. 2015; $7(3): 133-139$

52. Ye F, Wu J, Dunn T, Yi J, Tong X, Zhang D. Inhibition of cyclooxygenase-2 activity in head and neck cancer cells by genistein. Cancer Lett. 2004;211(1):39-46.

53. Kim YS, Choi KC, Hwang KA. Genistein suppressed epithelialmesenchymal transition and migration efficacies of BG-1 ovarian cancer cells activated by estrogenic chemicals via estrogen receptor pathway and downregulation of TGF-beta signaling pathway. Phytomedicine. 2015;22(11):993-999.

54. Regenbrecht CR, Jung M, Lehrach H, Adjaye J. The molecular basis of genistein-induced mitotic arrest and exit of self-renewal in embryonal carcinoma and primary cancer cell lines. BMC Med Genomics. 2008; $1: 49$

55. Tian T, Li J, Li B, et al. Genistein exhibits anti-cancer effects via downregulating FoxM1 in H446 small-cell lung cancer cells. Tumour Biol. 2014;35(5):4137-4145.
OncoTargets and Therapy

\section{Publish your work in this journal}

OncoTargets and Therapy is an international, peer-reviewed, open access journal focusing on the pathological basis of all cancers, potential targets for therapy and treatment protocols employed to improve the management of cancer patients. The journal also focuses on the impact of management programs and new therapeutic agents and protocols on

\section{Dovepress}

patient perspectives such as quality of life, adherence and satisfaction. The manuscript management system is completely online and includes a very quick and fair peer-review system, which is all easy to use. Visit http://www.dovepress.com/testimonials.php to read real quotes from published authors. 